\title{
O método fenomenológico em psicologia: uma leitura de Nilton Campos
}

\section{The phenomenological method in psychology: a Nilton Campos lecture}

\author{
Adriano Furtado Holanda* \\ Universidade Federal do Paraná - UFPA, Belém, Pará, Brasil
}

\begin{abstract}
RESUMO
Este trabalho de História da Psicologia é parte de um projeto maior, o qual se propõe a construir a história da fenomenologia no Brasil. Nilton Campos é - responsável pela primeira publicação que relaciona diretamente Fenomenologia ao campo da Psicologia em nosso país. O trabalho procura igualmente lançar luzes sobre as possíveis razões que justificariam o desenvolvimento tardio do pensamento fenomenológico no Brasil. Partindo da leitura de sua tese de concurso, de 1945, intitulada O Método Fenomenológico na Psicologia, o trabalho procura isolar as influências e os autores envolvidos no desenvolvimento de seu trabalho, buscando esclarecer os primeiros caminhos da psicologia fenomenológica no País. São apontadas as relações com o pensamento de Brentano e da Escola de Berlim, e finaliza por apontar a contemporaneidade do trabalho de Nilton Campos, seu lugar no contexto da história da psicologia brasileira, bem como seu legado em autores mais recentes, como Antonio Gomes Penna.
\end{abstract}

Palavras-chave: Fenomenologia, Psicologia, História da psicologia.

\begin{abstract}
This work in the perspective of the History of Psychology is a part of a larger project, that aims to build the history of phenomenology in Brazil. Nilton Campos is responsible for the first publication that directly relates to the field of psychology Phenomenology in our Country. The work also seeks to shed light on the possible reasons that would justify the late development of phenomenological thought in Brazil. Based on a reading of his thesis competition and entitled The Phenomenological Method in Psychology, the work seeks to isolate the influences and authors involved in the development of their work, seeking to clarify the first ways of phenomenological psychology in the country. We point out relations with the thought of Brentano and the School of Berlin, and concludes by pointing out the contemporary work of Nilton Campos, its place in the history of psychology in Brazil, as well as his legacy in more recent authors such as Antonio Gomes Penna.
\end{abstract}

Keywords: Phenomenology, Psychology, History of psychology. 
Este trabalho é, antes de tudo, uma homenagem ao Prof. Antonio Gomes Penna (1917-2010), Professor Emérito da UFRJ, que ajudou a construir a psicologia brasileira, a quem devo profunda admiração e gratidão por me haver presenteado, no ano de 2000, com um exemplar da obra de Nilton Campos.

\section{Introdução}

A proposta deste trabalho, que se enquadra na perspectiva da História da Psicologia, é de procurar traçar uma história do pensamento fenomenológico no Brasil. Trata-se, na verdade, de um destaque de um projeto maior, que visa construir um quadro da Fenomenologia no Brasil, de seus primórdios à atualidade, destacando os principais autores que desenvolveram o tema no país, bem como seus precursores e suas obras.

A idéia de construir um panorama histórico da Fenomenologia no Brasil não é nova, mas seguramente ainda demanda pesquisas. Na expectativa de poder contribuir com o debate nesta direção, nossa proposta se contextualiza na perspectiva de compreender dois aspectos dessa história, na igual expectativa de clarear o campo atual da fenomenologia brasileira.

Os dois aspectos a que nos referimos são os seguintes:

a) compreender o lugar da fenomenologia no pensamento brasileiro e tentar entender as razões pelas quais esse pensamento ainda não foi suficientemente desenvolvido em nosso país; e

b) compreender e tentar delimitar igual contexto no campo atual das Psicologias, e procurar entender os vieses decorrentes das diversas leituras que estas práticas ou teorias fazem da Fenomenologia.

Com relação à primeira expectativa, podemos dizer que já existem dados suficientes que ajudam a discriminar um viés dito "existencialista" para a fenomenologia no Brasil, como bem descreve Guimarães (1984, 2000), ao traçar o percurso histórico do pensamento fenomenológico no Brasil, e reconhecer o "ideário existencialista" como sua porta de entrada.

$\mathrm{Na}$ expectativa de traçar esse quadro, reconhecemos a figura de Raymundo de Farias Brito (1862-1917) como um precursor das idéias fenomenológicas no Brasil, como bem aponta a já conceituada bibliografia sobre esse autor (NOGUEIRA, 1962; GUIMARÃES, 1984, 2000). Todavia, é sob um "ideário existencialista" que a Fenomenologia ganha espaço no pensamento filosófico no Brasil, a partir da década de 1940 (GUIMARÃES, 1984, 2000).

Nomes como os de Euryalo Cannabrava (1908-1979) e Vicente Ferreira da Silva (1916-1963) aparecem - no terreno da filosofia - 
como os pioneiros nesta empreitada. Mas um terceiro nome ganha destaque ainda nos anos 1940, agora associado à emergente ciência psicológica, que é Nilton Campos, a quem iremos nos reportar neste momento. Um dos objetivos dessa apresentação é mostrar que a fenomenologia brasileira - tal qual o próprio projeto husserliano (HUSSERL, 1907/1990, 1910/1965, 1913/1985, 1928/2011; GOTO, 2008; HOLANDA; FREITAS, 2011) - desde cedo encontra solo fértil na Psicologia, e que esta pode ser considerada uma ciência privilegiada para o desenvolvimento das idéias fenomenológicas.

\section{Nilton Campos e o Pioneirismo na Fenomenologia}

As reflexões e as aplicações da Fenomenologia ao campo da Psicologia, têm no nome de Nilton Campos uma referência obrigatória e pioneira para grande parte dos psiquiatras e psicólogos brasileiros (MORUJÃO, 1990; GUIMARÃES, 2000), tendo-o igualmente como figura importante na construção da psicologia brasileira (CABRAL, 1964; PENNA, 1992, 2001).

Nilton Campos (1898-1963) nasceu no Rio de Janeiro e formou-se em Medicina na Faculdade Nacional de Medicina da antiga Universidade do Brasil (atual Universidade Federal do Rio de Janeiro), voltando-se para a neurologia e a psiquiatria. Foi o primeiro profissional a dedicar-se em tempo integral à Psicologia (CABRAL, 1964).

Após sua especialização em psiquiatria, Nilton Campos passa a integrar, já em 1924, a equipe da Colônia de Psicopatas do Engenho de Dentro ${ }^{1}$, na época dirigida por Gustavo Riedel que, em 1923, cria um laboratório de Psicologia. Com o apoio financeiro da Fundação Graffée-Guinle, o laboratório foi instrumentalizado e passou à direção de Waclaw Radecki, do qual passa a ser assistente. O Laboratório funcionava como instituição auxiliar médica, como núcleo de pesquisas científicas e como centro didático de formação de psicólogos (ANTUNES, 1998; PENNA, 2001; GOMES, HOLANDA; GAUER, 2004; CENTOFANTI, 2011).

Nilton Campos atua no Laboratório de Psicologia entre 1925 e 1937, com uma breve interrupção para viagem a estudos à Europa, em 1927 (CAMPOS, 1945), e por uma "missão profissional a São Paulo", em 1931 - onde, entre 1931 e 1933 - ajuda a organizar e fundar o Instituto Médico-Pedagógico Paulista - voltado para o trabalho com excepcionais -, com seu amigo Joaquim Penino (PENNA, 2001). Ainda em São Paulo, Nilton Campos participa da fundação da Sociedade de Neuropsiquiatria de São Paulo.

A partir de 1934, já de volta ao Rio de Janeiro, torna-se diretor do Serviço Neuropsicológico da Secretaria de Saúde e Assistência a Psicopatas do Distrito Federal (PENNA, 1992, 2001) e, no ano seguinte, é designado Diretor do Instituto de Psicologia de Assistência 
a Psicopatas, até 1937 (PENNA, 1992, 2001; GOMES, HOLANDA; GAUER, 2004; CENTOFANTI, 2011). Teve ainda passagem como professor do Colégio Pedro II e na Faculdade Nacional de Filosofia (em substituição a Lourenço Filho).

A partir de 1944 passa a exercer a cátedra de Psicologia Geral, na Faculdade Nacional de Filosofia, em substituição a André Ombredane. Esta cátedra foi conquistada através de concurso, quando apresentou sua tese, preparada em 1945, sob o título O Método Fenomenológico na Psicologia (CAMPOS, 1945; PENNA, 1992, 2001; GUIMARÃES, 2000; GOMES; HOLANDA; GAUER, 2004).

Numa sensível análise, Penna (1992) assinala - em A História da Psicologia no Rio de Janeiro - o esforço de Nilton Campos para encaminhar empiricamente o método fenomenológico. Um dos aspectos mais importantes do legado de Nilton Campos para a Fenomenologia e a Psicologia brasileiras é o fato que este antecipa, já em sua tese, a potencialidade desse método para a pesquisa psicológica, além de assinalar a proximidade com vários aspectos da Psicologia da Gestalt, destacando, contudo, uma percepção crítica da apropriação desta escola do método fenomenológico, quando aponta para a necessidade de modificação do método para melhor adequação à pesquisa em Psicologia.

O texto de Nilton Campos permanece, ainda hoje, como um texto atual e singular, pela sua clareza de exposições e, principalmente por sua visão crítica e aberta do método. Como assinala em sua tese, a "pesquisa fenomenológica procura descobrir, e não, inventar" (CAMPOS, 1945, p. 17). Defendendo uma posição compreensiva da pesquisa em psicologia - na mesma direção da proposição diltheyana - completa: "...a investigação fenomenológica tem que se afastar tanto da interpretação vulgar como da reflexão lógica sobre a natureza da realidade" (CAMPOS, 1945, p. 44).

A obra de Nilton Campos não se resume à sua tese. Além de diversos artigos empíricos publicados durante sua participação no Laboratório da Colônia de Psicopatas do Engenho de Dentro, seria importante destacar alguns artigos relacionados diretamente com a Fenomenologia, como o texto "A influência do pensamento de Dilthey na evolução da Psicologia como ciência autônoma", publicado no Anuário do Instituto de Psicologia em 1951; "Diferença entre descrição e explicação no estudo da Psicologia", de 1953; "Antecedentes filosóficos do isomorfismo gestaltista", de 1954 e "Importância e Significado da análise fenomenológica no estudo das ciências", de 1958, todos publicados no Boletim do Instituto de Psicologia.

\section{Sobre "O Método Fenomenológico em Psicologia"}


A tese de Nilton Campos, que iremos agora analisar, pode - e deve ser considerada desde já um clássico da história da psicologia brasileira. Não deixa de ser, igualmente, um escrito epistemológico que radica sua discussão nas diversas facetas de uma ciência principiante, ainda infante, e que discute os diversos modelos de apropriação que esta ciência busca em seu processo de autonomia. Neste particular, o cenário atual não está tão distante de suas discussões, principalmente quando discutimos o "fazer" e o "saber" da Psicologia. O autor também não se exime de questionar os alicerces ideológicos propugnados por determinados contextos de época.

Um dos aspectos mais significativos de sua tese é o fato de destacar as mais recentes reflexões - de sua época - no terreno da Psicologia e da Filosofia. Para tal, basta observarmos que na sua apresentação, Nilton Campos conta com comentários sobre sua obra, de autores renomados como Wolfgang Köhler e Gordon Allport, que congratulam o pesquisador brasileiro por seus esforços e reflexões.

O Método Fenomenológico em Psicologia é sua Tese apresentada à Cátedra de Psicologia Geral, ocupada interinamente desde 1944. Para efetivação desse trabalho, Nilton Campos (1945) ressalta suas consultas às fontes originais de Brentano e Husserl, feitas graças ao auxílio de Achim Fuerstenthal, que havia sido aluno de Herman Schmulenbach, na Basiléia - este, finalmente, antigo discípulo de Brentano. Sua Tese foi finalizada em março de 1945.

O trabalho está dividido em quatro capítulos:

1) Os Fundamentos da atitude fenomenológica;

2) A Investigação fenomenológica descritiva em psicologia;

3) A Legitimidade do método introspectivo; e,

4) As Modalidades da natureza intencional da consciência e a distinção entre função e conteúdo.

Iremos brevemente nos reportar cada capítulo, buscando discutir aspectos relevantes para a psicologia e a pesquisa psicológica, bem como apontando elementos que toquem a discussão filosófica. $O$ trabalho como um todo é uma defesa da fenomenologia e uma aproximação ao Gestaltismo mas, antes de tudo, é uma leitura sobre os fundamentos da Psicologia.

\subsection{Capítulo I - "Fundamentos da Atitude Fenomenológica"}

Nilton Campos (1945) começa sua discussão com a controvérsia sobre a natureza do objeto da psicologia. Fala, desde já, de "psicologias", o que contrariaria o reconhecimento da autonomia desta ciência, num texto absolutamente erudito e que demonstra relação direta com a literatura mais atualizada, à época. 
No debate epistemológico sobre a validade das ciências, chama a atenção para o critério de validade das hipóteses, que seria a concordância com os fatos e, portanto, deveria derivar da observação dos fenômenos, desprovida de julgamentos. Isto nos reporta à máxima husserliana sobre o positivismo. Em suas Ideen, de 1913, escreve Husserl:

Se por 'positivismo' entendemos o esforço, absolutamente livre de pré-julgamentos, para fundar todas as ciências sobre o que é 'positivo', ou seja, suscetível de ser tomado de maneira originária, somos nós os verdadeiros positivistas (HUSSERL, 1913/1985, p. 69).

Citando Charles Spearman, quando este aponta que uma ciência da mente se alia à experiência atual, evoca a máxima latina Hypothesis non fingo ("hipóteses, não faço" ou "não invento" ou "crio"), evocada por Isaac Newton quando inquirido sobre as "causas" da gravidade, cuja resposta seria "apenas" a constatação - a partir dos próprios fenômenos - da ocorrência de tal ou tal fato. Em nosso contexto, diz respeito ao recurso à experiência direta como base e solo fundamentador para uma ciência empírica.

Ainda nesta direção, toma o Gestaltismo como a escola que defende a experiência direta, e cita Koffka quando este diz que o método fenomenológico é a descrição ingênua e completa da experiência direta [em Princípios da Psicologia da Gestalt]. Mas o Gestaltismo não se satisfaz com a pura descrição e propõe nova hipótese naturalista, o isomorfismo. "Se o isomorfismo for válido, as funções do Sistema Nervoso apresentam as mesmas propriedades molares dos fenômenos mentais" (CAMPOS, 1945, p. 14).

Ao se referir a uma crítica contra o "naturalismo" gestaltista, recupera a tese de William MacDougall - colocada em Dynamics of the Gestalt-Psychology, de 1936 - quando este caracteriza a hipótese isomorfista como uma "nova versão do antigo paralelismo psicofisiológico" (CAMPOS, 1945, p. 14). Ficamos nos perguntando, o quanto que nossa cultura ou nossa modernidade se afastou dessas hipóteses polares e o quanto "superamos" esses modelos tidos como arcaicos na contemporaneidade. Em outras palavras, estamos afirmando a atualidade da crítica ao naturalismo, presente no pensamento fenomenológico, e a sua direção aos modelos contemporâneos de psicologia, além da inutilidade do debate em torno da "unidade" do pensamento psicológico.

Esta crítica ao naturalismo gestaltista se expressa muito bem na seguinte passagem: "Verificamos que os gestaltistas, apesar de repelirem o mecanicismo e o vitalismo, incidem na preocupação de formular outra teoria explicativa, levantando a suspeita de desejarem fisicalizar a psicologia" (CAMPOS, 1945, p. 14). 
Todavia, em sua própria defesa, os gestaltistas clamaram por uma filiação à realidade fenomenológica dos fatos da consciência, tomando-os como os objetos de investigação psicológica, como temos em Köhler e Koffka. O próprio Nilton Campos apresenta, em especial, dois textos como apoio: The Place of Values in a World of Facts, de Wolfgang Köhler; e Principles of Gestalt, de Kurt Koffka. Köhler mesmo reconhece que "(...) voltar às coisas-mesmas é uma arte difícil que Husserl chamou fenomenologia".

A esta defesa de uma perspectiva científica baseada na realidade concreta e desprovida de preconceitos, Nilton Campos (1945) ainda afirma que "(...) as doutrinas nenhum progresso real trazem para a ciência" (p. 16). Sem dúvida, diríamos que esta seria "a verdadeira" posição do cientista, muito próximo do que Carl Sagan - grande divulgador da ciência - delimitaria como o espírito "democrático" da ciência. Igualmente Husserl - em famosa epígrafe - concordaria, ao colocar que "o verdadeiro método segue a natureza das coisas a investigar, mas não segue os nossos preconceitos e modelos".

Nessa mesma perspectiva, um interessante paralelo traçado pelo autor, refere-se à posição de Bertalanffy sobre a dupla oposição relativa à crise da biologia: por um lado, uma idéia que reduz os processos biológicos a sua físico-química; por outro, princípios explicativos metafísicos, "divorciados dos fatos". "Assim, em lugar da ambicionada autonomia científica, o estudo dos fenômenos biológicos oscila entre a física e a metafísica" (CAMPOS, 1945, p. 16). Idêntica a posição da Psicologia, oscilando entre 0 materialismo e 0 espiritualismo, sendo que "ambos impedem a pesquisa dos fenômenos psíquicos livre de preconceitos" (CAMPOS, 1945, p. 16). Assim sendo, o mérito da atitude fenomenológica é exatamente a sua posição pré-teorética:

(...) a investigação fenomenológica não emprega nenhum método de análise dissociativa. Não disseca artificialmente a realidade para reduzi-la a elementos últimos. Limita-se a respeitar os fatos em seu aparecimento original, observandoos como eles são em si mesmos (CAMPOS, 1945, p. 17).

Distinto do idealismo kantiano, que separa os fenômenos do noumenon. Alia-se, todavia, a Leibniz, quando este se nega a considerar o mundo um caos. E na mesma direção da máxima: Alles was ist hat Sinn, "tudo se faz sentido"; ou, tudo tem um sentido. A posição, pois, da Fenomenologia - e que alicerça a colocação husserliana que a considera a "ciência das ciências" - é que "[A] pesquisa fenomenológica procura descobrir, e não inventar" (CAMPOS, 1945, p. 17). O próprio Husserl, em suas Investigações Lógicas, coloca que "o sistema inerente à ciência - naturalmente a verdadeira ciência - não é uma invenção nossa, mas reside nas 
coisas, das quais as descobrimos simplesmente", como cita Campos (1945, p. 18). E continua Husserl (1900/2005): "(...) o domínio de uma ciência é uma unidade objetiva fechada; não reside no nosso arbítrio onde e como delimitamos o domínio da verdade" (p. 31).

Campos (1945) chama a atenção para esta posição husserliana, quando este afirma que:

Toda a teoria nas ciências empíricas é meramente
pressuposta. Ela não fornece explicação a partir das leis
fundamentais intelectivamente certas, mas somente
intelectivamente prováveis. Assim, também as próprias
teorias são somente de probabilidade intelectiva, teorias
somente provisórias, não definitivas (HUSSERL, 1900/2005,
p. 255).

Percebe-se, aqui, a atualidade do pensamento fenomenológico expresso por Nilton Campos. Ainda, a fenomenologia investiga a realidade do mundo natural, sem duvidar de sua existência. Esta é a própria afirmação do mundo que faz Husserl nas Idéias, ao se referir à epoche:

(...), eu não nego este "mundo", como se fosse um sofista; eu não coloco sua existência em dúvida, como se fosse um cético; mas eu opero a epoche "fenomenológica" que me impede de todo julgamento sobre a existência espáciotemporal (HUSSERL, 1913/1985, p. 102-103).

A Fenomenologia é, pois, contrária a qualquer forma de ceticismo. Em apoio a esta idéia, Nilton Campos ainda nos lembra Albert Einstein, quando este diz que dificilmente alguém contemplaria as estrelas sem crer em sua existência; e Max Planck, que afirma que a ciência também precisa de espíritos crentes. "A investigação fenomenológica funda-se na consideração da realidade de todos os seres, sejam propriamente reais, no sentido de rerum natura, ou puramente ideativos" (CAMPOS, 1945, p. 19). Assim, um centauro (como exemplifica Sartre), ou a figura de Júpiter (outro exemplo, este de Husserl), são tão reais como objetos da consciência, quanto o corpo que vivo, a folha de papel que tenho nas mãos, a inflação que corrompe minhas economias ou o delírio do sujeito delirante.

Nilton Campos - ainda em seu exercício de erudição - cita Taine, que num escrito de 1870, sobre a inteligência, quando este aponta a percepção exterior como uma "alucinação", mas que primeiramente se apresenta como uma sensação (CAMPOS, 1945). Mas o próprio Husserl já afirmara que não vemos a sensação das cores, mas as coisas coloridas. "A teoria alucinatória do mundo exterior é [pois] incompatível com a atitude fenomenológica" (CAMPOS, 1945, p. 20). A atitude fenomenológica é a abertura do sujeito ao mundo, em intrínseca relação com este. Homem e mundo se constituem. 
O próprio William James, ao falar sobre as alucinações, afirma ser um erro considerar que as mesmas têm ausência de estímulos objetivos. A fenomenologia admite - ao mesmo tempo - tanto a realidade da percepção exterior, quanto a objetividade dos conteúdos mentais. Para apontar a "natureza" da investigação fenomenológica da realidade, Nilton Campos recorre a Binet, e recorre ainda à história desse gênio da psicologia, que - primeiramente ao adotar uma perspectiva atomística, considerando a percepção como uma "síntese de sensações e imagens" - ao visitar o laboratório de Leipzig, em 1893 -, e mobilizado por uma grande decepção decorrente desta visita, modifica radicalmente seu pensamento quanto à aplicação do método experimental ao progresso da Psicologia. Parte daí para uma discussão com Oswald Külpe, o que permite a Binet uma nova concepção de método experimental, agora liberto do fisiologismo, e que levou o nome de "introspecção dirigida", sendo publicado em 1903, em L'Étude Expérimentale de l'intelligence.

\begin{abstract}
A intransigência de Wundt relativamente ao emprego do método experimental na pesquisa dos fenômenos mentais superiores precipitara o aparecimento de um novo centro de estudos, em Würzburg, sob a direção de Külpe, desenvolvendo-se aí, a partir de 1901, a chamada 'Denkenpsychologie' ["Psicologia do pensamento"] (CAMPOS, 1945, p. 23).
\end{abstract}

Dissidência esta que teria favorecido Brentano, que fizera sérias críticas à obra wundtiana - Grundzüge der physiologischen Psychologie - no seu caráter de restrição à pesquisa associada à fisiologia. Em seu lugar, Brentano coloca a "experiência", como a apreensão direta dos fenômenos. Mesmo que Boring (1929) aponte que a "psicologia empírica" de Brentano não seja uma "psicologia experimental", conclui-se que a própria experimentação sistemática precisa da descrição, sendo assim - segundo Nilton Campos (1945) - "indubitável que as descobertas realizadas nos laboratórios de Würzburg e Graz foram influenciadas pelas idéias de Brentano, que clamavam pela emancipação da pesquisa psicológica do naturalismo experimental" (p. 24). Foi a "conversão" brentaniana ao conceito escolástico de intencionalidade que possibilitou 0 advento da Fenomenologia.

Campos (1945) ainda ressalta a interessante proximidade entre os pensamentos de Husserl e de Ehrenfels, mais especificamente no que o primeiro escreve em sua Filosofia da Aritmética, de 1891; e no que o segundo escreve em 1890, sobre as Gestalt-qualitäten. E, igualmente, chama-nos a atenção para esse importante movimento de renovação e revisionismo dos estudos psicológicos, em fins do século XIX, representado por figuras proeminentes como Henri Bergson (em Les Données Immédiates de la Conscience, 1889), 
William James (em Principles of Psychology, 1890) e Wilhelm Dilthey (em Ideen über eine beschreibende und zergliedernde Psychologie [Idéias concernentes a uma psicologia descritiva e analítica], de 1894), em aberta "oposição ao mecanicismo dominante [que] dão origem respectivamente a novos critérios teleológicos sobre o caráter qualitativo dos fenômenos mentais, a natureza dinâmica da consciência e a diferença entre explicar e compreender a atividade mental" (CAMPOS, 1945, p. 25).

Direta ou indiretamente, Nilton Campos antecipa uma discussão sobre o método "qualitativo" em pesquisa, que somente toma força na década de 1980, cerca de trinta anos depois, e que hoje podemos afirmar - encontra-se solidificado.

Imediatamente a influência dessas idéias encontra terreno fértil na psicopatologia - até então dominada pela "anatomia patológica" através de Karl Jaspers, como podemos observar em sua proposta de uma psico-patologia, a partir de uma "fenomenologia descritiva", como a apresentação dos estados psíquicos vivenciados pelos pacientes. Nisto - escreve Jaspers (1987) - "nos servem de ajuda, sobretudo, as descrições próprias dos pacientes (...)" (p. 75).

Retomemos Nilton Campos (1945), em sua defesa de uma identidade para a ciência psicológica, com uma base fenomenológica: "A atitude fenomenológica defende o direito de as ciências possuírem um objeto específico e inconfundível (...). [Mas] o verdadeiro espírito científico consiste no respeito aos limites naturais que distinguem entre si as ciências, a fim de consagrá-las em sua autonomia" (p. 28). Com isto, Nilton Campos afirma a irredutibilidade de uma ciência à outra e, portanto, defende - à luz da fenomenologia - a abertura da ciência psicológica e, por conseguinte, a definição husserliana da fenomenologia como "ciência das ciências".

\subsection{Capítulo II - "A Investigação Fenomenológica Descritiva e o Conceito de Explicação em Psicologia"}

O segundo capítulo versa, sobretudo, - nas palavras de Nilton Campos - sobre o "problema da consciência", que seguiria, na Psicologia, segundo duas diretrizes, uma estática e uma dinâmica. A psicologia clássica ficou num contexto estático - elementarista, ou "atomística" e, portanto, próxima dos determinismos elementaristas (PENNA, 1997) -, tentando dissecar a consciência, decompondo-a em elementos, "à maneira do físico e do químico", seguindo um modelo próximo ao "atomismo psicológico". Na mesma direção teríamos a perspectiva de Watson e a negação do subjetivismo na psicologia, negando a especificidade dos fatos psíquicos; e desenvolvendo uma "psicologia apsicológica".

Novamente temos aqui a questão do método psicológico trazido à baila. Todavia, coloca Nilton Campos (1945), a proposta de Wundt de 
uma "síntese criadora", que fez com que a psicologia experimental não excluísse totalmente a natureza específica dos fenômenos mentais.

O behaviorismo se distinguiria de uma "psicologia da consciência", por negar as sensações e a associação como objeto de pesquisa psicológica. Mas o behaviorismo permanece com o mesmo preconceito explicativo da atividade mental a partir do atomismo motor. "Em substituição ao atomismo interno da consciência próprio da psicologia associacionista, Watson propõe o atomismo periférico do comportamento. Em lugar do átomo-sensação, surge o átomoreflexo como elemento explicativo", diz Campos (1945, p. 34).

William James, já em 1904, afirmara o absurdo de se negar a existência da consciência, dado que os "pensamentos existem". Todavia, nega seu caráter de "entidade" e, afirmando-a como uma função, nega - portanto - a consciência como matéria. Substitui, assim, o conceito de uma entidade estática por uma função dinâmica:

\begin{abstract}
Deixe-me logo explicar que eu quero dizer apenas para negar que a palavra [consciência] significa uma entidade, mas a insistir mais enfaticamente, que não resiste a uma função. (...) "Consciência" é suposto necessário para explicar o fato de que as coisas não apenas são, mas são reportadas, são conhecidas (JAMES, 1904, p. 477).
\end{abstract}

Mesmo negando o caráter substancial da consciência, James - ao afirmá-la como função - finda por posicioná-la como um ente, como uma realidade, na acepção fenomenológica; sendo, portanto, um "objeto" suscetível de investigação. "James, afirmando ser a consciência condição necessária para a revelação da existência das coisas, assegura-Ihe a propriedade de 'coisa' também existente no mundo dos fatos" (CAMPOS, 1945, p. 35).

Esta discussão colocaria William James ao lado da perspectiva fenomenológica: "(...) a acusação de James contra o atomismo psicológico, que abandonara o verdadeiro método empírico de investigação, exprime uma atitude fenomenológica, que o torna precursor das idéias de Husserl" (CAMPOS, 1945, p. 37). Ademais, o próprio Husserl afirmara a importância do valor do Principles of Psychology, para o campo da psicologia descritiva. Lembremos que James, ao se referir ao problema da consciência, usa a metáfora de um rio para falar da "corrente de consciência", e ao expressar-se sobre a vivência do tempo, afirma que nossa experiência imediata não se dá de modo atomístico, visto que temos um sentido de passado e um sentido de futuro diretamente dados. "Para usar a frase de William James, nossa experiência do presente não é o fio de uma faca, mas um telhado de duas águas. Tudo o que é dado para nós na percepção é dado como sumindo e também como chegando na presença" (SOKOLOWSKI, 2007, p. 147). Ainda, afirmando que a 
propriedade reflexiva da consciência não é primitiva, James se aproximaria de Piaget, quando este diz que a consciência de si nasce da dissociação do eu com a realidade, reiterando, pois, o caráter dinâmico da consciência.

"O problema do conhecimento de si mesmo foi profundamente estudado por Descartes, que, afinal, esclareceu a natureza do fenômeno como sendo uma apreensão imediata e, não, o resultado de um raciocínio dedutivo" (CAMPOS, 1945, p. 39-40). Ora, isto implica dizer que esta apreensão "se dá", ou seja, se mostra como uma coisa conhecida de si. Em outras palavras, a conclusão que se tira de uma clássica epígrafe como "penso, logo sou" ou "existo", não se dá por silogismo ou por uma conclusão tirada do seu pensamento, mas de uma coisa conhecida em si, diz Campos (1945). "Vemos, portanto, Descartes demonstrando que a consciência de si mesmo é uma evidência assertórica ${ }^{2}$, realizando-se sem intermediário, pois resulta de uma percepção interna imediata" (p. 40). Eis de volta a experiência imediata sendo reabilitada.

Campos (1945) ainda caminha na direção da análise de uma crítica ao mecanicismo, unindo - segundo ele - Locke a Descartes, quando aquele aponta que o conhecimento do próprio ser se dá por intuição, enquanto que o conhecimento das coisas se dá por sensação (como escreve Locke em An Essay Concerning Human Understanding, de 1690). A coincidência do pensamento de Locke com a fenomenologia iria mais além, segundo Campos (1945), como quando o filósofo inglês defende que a ideia seria o "objeto" do pensamento, ou ainda, que seria sobre a experiência que nosso conhecimento se funda. Isto marca uma filiação "empirista" da fenomenologia - especialmente às figuras de Locke e de Hume (DEPRAZ, 2007).

Assim, Campos (1945) reitera que a consciência apresenta um movimento incessante, deslocando-se dos pólos objetivo e subjetivo. Posteriormente, define experiência como o "fenômeno de sentir ou viver os fatos, de maneira espontânea e imediata" (p. 43). Assim, são vivências tudo o que tem lugar na consciência: as percepções, as representações, a imaginação, a fantasia, o pensamento, etc. E igualmente são vividas suas partes componentes e seus conteúdos. Em suas palavras, seria característico da consciência, ser "um fluxo multiforme de vivências mentais" (CAMPOS, 1945, p. 43).

No caso das vivências - ou experiências da percepção externa, como assinala Campos (1945) - a apreensão de objetos externos é um conteúdo "vivido" ou "experimentado",

(...) portanto, consciente, tanto quanto 0 ato dessa apreensão. Lembremos que a visão alucinatória de um conteúdo colorido sine materia é também uma vivência fenomenológica real. A ausência do excitante físico material não impede que a vivência colorida alucinatória seja um fato. A investigação fenomenológica das vivências tem que se 
afastar tanto da interpretação vulgar como da reflexão lógica sobre a natureza da realidade (p. 44).

Assim, diz Nilton Campos (1945), qualquer discussão sobre a materialidade ou a substancialidade dos fatos psíquicos teria um caráter metafísico. Em outras palavras, a fenomenologia não se preocuparia com os fatos em si, mas com os sentidos dos fatos. Não importa se há ou não há o azul ou o vermelho nos objetos, estas são qualidades da consciência e, portanto, realidades imediatas e distintas uma das outras.

Brentano mesmo já afirmara que, quando dizemos que apreendemos os fenômenos psíquicos pela percepção interna, afirmamos igualmente que essa percepção é uma evidência imediata. Assim, a existência coincide com os próprios fenômenos. Aqui, "percepção interna" representa o sentido da própria Psicologia, para Brentano: "Psicologia é a ciência da vida interior das pessoas [Seelenleben], isto é, a parte da vida captada através da percepção interior [Innere Warhnemung]" (BRENTANO, 1995, p. 3)

No debate epistemológico sobre a validade das percepções - interna ou externa - enquanto Brentano duvidava da percepção externa, e Watson da percepção interna, Köhler e Husserl consideravam a realidade de ambas as vivências. "Husserl - diz Campos - confirma que, no caso da percepção externa, os conteúdos sensíveis procedentes do mundo físico são igualmente vividos, possuindo a mesma indiscutível evidência peculiar à experiência interna" (CAMPOS, 1945, p. 48).

Esse capítulo versa, sobretudo, das polêmicas relativas às apropriações de método e às epistemologias diversas, ou seja, sobre objeto e método da Psicologia. Nilton Campos (1945) busca, ainda, defender o gestaltismo da acusação de naturalização, colocando que "os fenômenos qualitativos e específicos da atividade mental são diferentes dos processos físicos" (p. 54). E continua, dizendo:

\begin{abstract}
A explicação isomorfista não significaria (...), uma conversão do mental em físico. Apenas pretenderia ser uma hipótese destinada a interpretar os processos fisiológicos cerebrais sotopostos aos fenômenos psíquicos, segundo o modelo fornecido pelas teorias da moderna física dinâmica, sem afetar a autonomia da psicologia (CAMPOS, 1945, p. 54).
\end{abstract}

E, vale a pena assinalar, essa perspectiva é a mesma adotada por Kurt Lewin, que se apropria de terminologias das ciências físicas, como "campo", "valência", etc. Mas Köhler - e com ele a Escola de Berlim - não se satisfez com um estudo puramente descritivo e buscou tornar a psicologia uma ciência explicativa, tendo suas hipóteses sido extraídas da física, "o modelo indiscutível de exatidão científica" (CAMPOS, 1945, p. 55). Assim, o Gestaltismo seria 
rigorosamente fenomenológico em sua perspectiva descritiva, mas se afastaria dessa posição ao intentar uma teoria explicativa, abdicando da psicologia em favor da fisiologia e da física.

\subsection{Capítulo III - "Legitimidade do Método Introspectivo"}

Ainda sobre a questão da consciência e sobre a possibilidade de fundamentá-la como objeto de uma ciência, Nilton Campos resgata agora a contribuição de Brentano para uma psicologia de orientação fenomenológica.

Ribot já anunciara o nome de Brentano como aquele que funda uma orientação que exclui a metafísica e a fisiologia do campo científico da psicologia e, portanto, inaugura uma perspectiva autônoma para esta (CAMPOS, 1945). Apropriando-nos das mesmas palavras do filósofo, em seu prefácio no longínquo ano de 1874, diz-nos Brentano (1874/2008): "Eu me coloco, em psicologia, do ponto de vista empírico. Meu único mestre é a experiência" (p. 11).

$\mathrm{Na}$ perspectiva brentaniana, temos a distinção entre percepção interna e observação interior. A primeira implica numa clivagem da consciência em duas partes simultaneamente existentes: uma que observa e outra que é observada; assim, esta perspectiva - que implicaria "num desdobramento da consciência em sujeito e objeto simultâneos, é uma indiscutível impossibilidade. A observação interior é somente concebível no sentido de uma retrospecção, pelo recurso da evocação mnemônica" (CAMPOS, 1945, p. 65). A consciência "vive", pois, seus fenômenos num "suceder ininterrupto". Assim:

Todas as objeções contrárias ao valor científico do método introspectivo têm de cessar diante dos critérios fenomenológicos, que vem restaurá-lo como um dos recursos imprescindíveis de pesquisa psicológica (CAMPOS, 1945, p. 69).

Aqui, Campos retoma a grande contribuição de Brentano, em seu texto de 1874 - A Psicologia do Ponto de Vista Empírico-em que se formula a noção de intencionalidade, que conduz à superação do caráter "estático" da consciência, para uma perspectiva "dinâmica" da mesma. Decorre daí que "(...) a psique humana se estrutura dinamicamente em atos, todos referidos a objetos imanentes à consciência" (MACIEL, 2003, p. 36).

\subsection{Capítulo IV - As Modalidades da Natureza Intencional da Consciência e a Distinção entre Função e Conteúdo}

No capítulo IV, Nilton Campos recupera a noção fenomenológica de intencionalidade como a característica da consciência ser consciência de alguma coisa, e nos recorda que este conceito fundamental fora estudado por Brentano, a partir de seus estudos da Escolástica 
medieval, em particular na noção de intentio, que exprime a direção espontânea da consciência para algo, e é expressa na máxima: Actus mentis quo tendit in objectum. Ressalta ainda que a intentio é absolutamente distinta do vocábulo intenção, que tem um sentido volitivo (CAMPOS, 1945), e ainda recupera uma advertência de Gaós - tradutor para o espanhol - de que este conceito, para os escolásticos medievais, refere-se a uma in-existencia intencional, que implica em uma existência-em.

Por fim, ressalta outra distinção fundamental em Brentano, entre ato psíquico e seu respectivo conteúdo, que teria influenciado diretamente as escolas de Graz e de Wurzburg. Apenas a título de ilustração, convém lembrar que a Escola de Graz se desenvolveu em torno de Alexius von Meinong. Dentre seus discípulos e colaboradores, destacaram-se Eduard Martinak e Stephan Witasek, além de Vittorio Benussi. Já a Escola de Würzburg girou em torno de Osvald Külpe, da qual se destacaram August Messer, Karl Bühler e Narziss Ach.

$\mathrm{Na}$ discussão acerca dos "atos da consciência", Campos (1945) assinala que Husserl, nas suas Investigações Lógicas, considera ato como equivalente a vivência intencional: "Na percepção da trovoada coexiste a consciência virtual do silêncio 'interrompido' pelo trovão, cujo ruído não constitui, pois, apenas uma apreensão atual pura ou isolada" (p. 85). Consciência, pois, é uma corrente contínua e indissociável de vivências e experiências.

Husserl - posteriormente, em suas Ideen - amplia a noção de intencionalidade, demonstrando que:

(...) a corrente da consciência encerra vivências ou experiências atuais e virtuais, distinguindo o conceito atual e o conceito potencial da intencionalidade. Na percepção dos objetos, realizamos uma apreensão atual e virtual concomitantes, justificando aquilo que Husserl denominou de "background" do campo da consciência (CAMPOS, 1945, p. 82).

Husserl admite, assim, a percepção de modo intuitivo, sendo esta intuição dotada das mesmas propriedades intencionais - de dirigir-se para algo - que os atos da consciência cognitiva. Nas palavras do próprio Husserl: "É a intencionalidade que caracteriza a consciência no sentido extremo e que autoriza ao mesmo tempo a tratar todo o fluxo do vivido como um fluxo de consciência e como a unidade de uma consciência" (HUSSERL, 1913/1985, p. 283).

\section{Considerações Finais}


O trabalho de Nilton Campos, embora não se proponha a um exaustivo exame, nem da questão do método em Psicologia, nem dos pressupostos da Fenomenologia; não sendo assim, exatamente um tratado numa ou noutra perspectiva, aponta - todavia - para alguns elementos que devem ser destacados.

O primeiro deles refere-se ao seu caráter de contemporaneidade. Já em 1945, o autor demonstra uma interessante apropriação de literaturas cruciais nos campos filosófico e psicológico, colocando-se de certa forma - na vanguarda de um pensamento que no Brasil acabou sendo construído por vias que chamaríamos "acessórias" ou "suplementares", quais sejam, os dos pensamentos existencialistas (em suas diversas formas, mas especialmente a partir de Sartre) e o de Heidegger (com toda a gama de sua especificidade).

Com isto, queremos apontar para um fato que consideramos crucial para a compreensão do legado da fenomenologia, que foi o de ter Nilton Campos, em certa medida, trilhado o caminho dos fundamentos, aqui no caso, relativos aos pensamentos de Brentano e de Husserl.

$\mathrm{Na}$ medida em que consideramos as diversas perspectivas existencialistas do século passado como construções devedoras diretamente - da fenomenologia husserliana, este fato ganha mais destaque. Reconhecemos que a fenomenologia (a partir de sua noção central de intencionalidade), radicalizada desemboca, necessariamente, numa filosofia da existência - idéia esta compartilhada por Merleau-Ponty e por Pierre Thévenaz (RICOEUR, 2009).

O pioneirismo de Nilton Campos ganha mais destaque se considerarmos que não só seus estudos estão referentes à "atualidade" do pensamento fenomenológico à época - lembremos que a primeira referência direta a Husserl no Brasil data de 1941 (como Euryalo Cannabrava), de forma indireta - mas, principalmente pelo fato de ter sido, provavelmente, o primeiro brasileiro a citar fontes diretas da fenomenologia husserliana.

Todavia, não podemos nos furtar a uma apreciação de algumas limitações de sua obra sem, contudo, reconhecer os próprios limites de seu tempo. Uma delas é o fato de não se ter uma apropriação da obra de Husserl como um todo, o que é absolutamente natural pelo fato do ineditismo de muitos dos textos husserlianos, que somente vieram a público, décadas depois. Em seu texto, Campos (1945) cita textualmente os seguintes textos de Husserl: as Investigações Lógicas (de 1900), as Idéias (de 1913, em seu primeiro volume ${ }^{3}$ ), e as Meditações Cartesianas (de 1929).

Por focar sua atenção na questão da ciência, Nilton Campos não explora a totalidade desses mesmos textos, deixando de lado questões importantes para a própria psicologia, como a questão da consciência pura ou transcendental, ou mesmo a discussão entre a 
atitude natural e a atitude fenomenológica, ou ainda o problema das reduções fenomenológicas (todos esses temas estão presentes no primeiro volume das Ideen); e a determinação da consciência como intersubjetividade (presente nas Meditações Cartesianas).

Nada disto invalida ou diminui o trabalho de Nilton Campos. Sua obra - bem como seu trabalho legado em tantos outros escritos - precisa ser resgatada, tanto em conteúdo, quanto em forma, o que nos ajudaria a construir um solo de perspectivas de leituras da fenomenologia, aplicadas à psicologia, menos enviesadas ideologicamente, e mais coerentes com a lição husserliana de retorno às coisas mesmas.

\section{Referências}

ANTUNES, M. A. M. A Psicologia no Brasil. Leitura histórica sobre sua constituição. São Paulo: Unimarco/Educ, 1998.

BORING, E. A History of experimental psychology. New York: Appleton-Century-Crofts, Inc., 1929.

BRENTANO, F. C. Descriptive psychology. London: Routdlege, 1995.

BRENTANO, F. C. Psychologie du point de vue empirique. Paris: Librairie Philosophique J.Vrin (Original publicado em 1874), 2008.

CABRAL, A. Nilton Campos (1898-1963). Jornal Brasileiro de Psicologia, São Paulo, v. 1, n. 2, p. 3-12, 1964.

CAMPOS, N. O Método fenomenológico na psicologia. 96f. Tese de Concurso apresentada à Cátedra, Universidade do Brasil, Rio de Janeiro, 1945.

CENTOFANTI, R. Laboratório de Psicologia da Colônia de Psicopatas do Engenho de Dentro - 1924-1932. In: JACÓ-VILELA, A. M. (Org.). Dicionário histórico de instituições de psicologia no Brasil [pp. 355-356]. Rio de Janeiro: Imago / Brasília: Conselho Federal de Psicologia, 2011.

DEPRAZ, N. Compreender Husserl. Petrópolis: Vozes, 2007. GOMES, W. B.; HOLANDA, A. F.; GAUER, G. História das Abordagens Humanistas em Psicologia no Brasil. In: MASSIMI, M. (Org.). História da psicologia no Brasil do século XX. São Paulo: E.P.U., 2004, p. 105-129.

GOTO, T. A. Introdução à psicologia fenomenológica. São Paulo: Paulus, 2008.

GUIMARÃES, A. C. Farias Brito e as origens do existencialismo no Brasil. São Paulo: Editora Convivio, 1984.

GUIMARÃES, A. C. O Pensamento Fenomenológico no Brasil. Revista Brasileira de Filosofia, v. L., Fasc. 198, p. 258-267, 2000.

HOLANDA, A. F.; FREITAS, J. L. Fenomenologia e Psicologia. Vinculações. In: PEIXOTO, A. J. (Org.). Fenomenologia. Diálogos Possíveis Campinas: Alínea / Goiânia: Editora da PUC Goiás, 2011, p. 97-112. 
HUSSERL, E. A Filosofia como ciência de rigor. Coimbra: Atlântida, 1965. (Original publicado em 1910).

HUSSERL, E. Idées directrices pour une phénoménologie et une philosophie phénoménologique pures. Paris: Gallimard, 1985. (Original publicado em 1913).

HUSSERL, E. A ideia da fenomenologia. Lisboa: Edições 70, 1990. (Original publicado em 1907).

HUSSERL, E. Investigações lógicas. Lisboa: Phainomenon, 2005. (Original publicado em 1900).

HUSSERL, E. Psychologie phénoménologique (1925-1928). Paris: J. Vrin, 2011. (Original publicado em 1928).

JAMES, W. Does Consciousness Exists? Journal of Philosophy, Psychology, and Scientific Methods, v. 1, p. 477-491, 1904. JASPERS, K. Psicopatologia geral. Rio de Janeiro: Atheneu, 1987. MACIEL, J. C. (2003). Franz Clemens Brentano e a Psicologia. In: BRUNS, M. A. de T.; HOLANDA, A. F. (Orgs). Psicologia e fenomenologia. reflexões e perspectivas [pp. 27-40]. Campinas: Alínea, 2003.

MORUJÃO, A. F. (1990). Fenomenológico (Movimento). In: Logos. Enciclopédia Luso-Brasileira de Filosofia. Lisboa: Verbo, 1990, p. 495503.

NOGUEIRA, A. Farias Brito e a filosofia do espírito. Rio de Janeiro: Livraria Freitas Bastos, 1962.

PENNA, A. G. A Dispersão do Pensamento Psicológico e a Impossibilidade de sua Unificação. In: PENNA, A. G. Repensando a psicologia. Rio de Janeiro: Imago, 1997, p.57-92.

PENNA, A. G. História da psicologia no Rio de Janeiro. Rio de Janeiro: Imago, 1992.

PENNA, A. G. Nilton Campos. In: CAMPOS, R. H. F. (Org.). Dicionário biográfico da psicologia no Brasil. Rio de Janeiro: Imago / Brasília: Conselho Federal de Psicologia, 2001, p. 112-114. RICOEUR, P. Na escola da fenomenologia. Petrópolis: Vozes, 2009.

SOKOLOWSKI, R. Introdução à fenomenologia. São Paulo: Loyola, 2007.

Endereço para correspondência

Adriano Furtado Holanda

Departamento de Psicologia e Mestrado em Psicologia, Universidade Federal do Paraná. Praça Santos Andrade, 50 - Sala 215 (Ala Alfredo Buffren). 80060-240, Curitiba, PR, Brasil

Endereço eletrônico: aholanda@yahoo.com

Recebido em: 19/10/2011

Reformulado em: 04/06/2012

Aceito para publicação em: 05/06/2012

Acompanhamento do processo editorial: Ana Maria Lopez Calvo de Feijoo 


\section{Notas}

*Doutor em Psicologia pela PUC-Campinas e Professor Adjunto do Departamento de Psicologia e do Programa de Pós-Graduação em Psicologia da Universidade Federal do Paraná.

${ }^{1}$ Fundada em 1910. O Laboratório de Psicologia é posteriormente transformado em Instituto de Psicologia, subordinado - em 1932 - ao Ministério da Educação e Saúde Pública, e em 1937, é incorporado à antiga Universidade do Brasil.

${ }^{2}$ Asseverativa, que contém afirmação.

${ }^{3}$ Merece destaque o fato que o segundo volume das Ideen, que trata da questão da constituição e tem implicações fundamentais em problemas como subjetividade, intersubjetividade e corporeidade, e que é central para a compreensão do sentido do "mundo-vida" na obra de Husserl, somente veio a público em 1952, com sua primeira tradução francesa em 1982. 